\title{
ESTATIZAÇÃO, POLÍTICAS SOCIAIS E LAZER NO BRASIL ${ }^{1}$
}

Recebido em: 27/05/2010

Aceito em: 27/10/2010

Dulce Filgueira de Almeida

Universidade de Brasília - UNB

Brasília - DF - Brasil

RESUMO: O trabalho analisa o papel do Estado e das políticas sociais, tendo como foco a questão do lazer e os programas governamentais no Brasil. Trata-se de um trabalho baseado em pesquisa documental, cuja reflexão se assenta em autores como Bobbio (1990), Burzstin (1998), Santos (1997) e Mascarenhas (2004). Os eixos norteadores do debate estão centrados nos conceitos de Estado, políticas sociais, participação democrática e lazer. Com base na reflexão apresentada, propõe-se a construção de uma compreensão crítica sobre o cenário da institucionalização de políticas sociais que focalizam o lazer no Brasil.

PALAVRAS-CHAVE: Estado. Política Social. Atividades de Lazer.

\section{STATIZATION, SOCIAL POLICES AND LEISURE IN THE BRAZIL}

ABSTRACT: This paper analyses the role of the State and the social polices having as center the leisure and the governmental programs in the Brazil. It was a work based on documental research, supported by authors such as Bobbio (1990), Burzstin (1998), Santos (1997) and Mascarenhas (2004). The theoretical reference was centered in categories such as: State, social polices, participative democracy and leisure. It is proposed a critical comprehension of the scene of the institutionalization of the social polices in Brazil that has its' focus on the leisure.

KEYWORDS: State. Social Policy. Leisure Activities.

\section{Introdução}

O tema do Estado é fruto de intensos debates nos campos das teorias política e

social. Desde os pensadores clássicos como Maquiavel, Hobbes, Locke e Rousseau,

\footnotetext{
1 Este trabalho apresenta reflexões construídas com base em estudos realizados na Universidad de Salamanca-España, entre janeiro e dezembro de 2007. Contou-se com a concessão de bolsa de pósdoutoramento da Coordenação de Aperfeiçoamento de Pessoal de Nível Superior - Capes. É parte de um projeto maior da Rede Cedes/UnB, que recebe financiamento da Financiadora de Estudos e Projetos FINEP do Ministério da Ciência e Tecnologia do Brasil.
} 
passando por Marx, Weber, Gramsci e Poulantzas, as visões sobre o Estado são múltiplas ao tempo em que substantivas.

Diante da importância que se verifica na discussão sobre o papel do Estado na atualidade, tendo em vista o ressurgimento da sociedade civil, que se traduz na reafirmação de valores do autogoverno, da ampliação de espaços de subjetividade, de participação coletiva e da organização autônoma dos interesses e dos modos de vida (SANTOS, 1997), analisar o Estado e as políticas sociais parece provocador em um contexto de tensionamento entre a adoção de uma política voltada para a economia de mercado e que preconiza a desregulação e uma tendência - relativamente recente - da razão estatizante.

Por outro lado, no quadro que se enuncia - atual configuração do Estado brasileiro (1996-atual) - pautar políticas que contemplem direitos sociais como o lazer pode expressar uma maneira diferenciada de compreender o Estado, mas também pode significar a compreensão de estratégias voltadas para a adoção de um modelo diverso de gestão que, ainda que contemple a participação da sociedade civil no processo, pode representar uma espécie de atenção assistencial, ao invés de busca de empoderamento ${ }^{2}$ e autonomia.

Vale assinalar ainda que a conformação do Estado brasileiro no período atual atende, particularmente, a dois vieses, ou seja, tem-se, de um lado, o aparelho estatal que assume para si funções voltadas para a universalização e, de outro, a necessidade de assegurar o mínimo de regulação em determinados setores. Nesta direção, as políticas de cunho social, entendidas como aquelas que possibilitam a concretização de direitos sociais, tais como: saúde, educação, meio ambiente, proteção social e esporte e lazer

\footnotetext{
${ }^{2}$ Utilizo essa expressão na falta de outra mais apropriada.
} 
parecem estar em sintonia com outro desenho de Estado, que passa a se configurar a partir de 1996 e se consolida nas duas gestões do Governo Lula da Silva (2003-atual).

Neste ínterim, aspectos como a criação do Ministério do Esporte e a atenção dada ao lazer como direito social podem sinalizar que o Estado brasileiro busca a universalização do acesso a alguns direitos sociais, indicando, em alguma medida, a ampliação do espaço para o exercício da cidadania (SANTOS, 1997). Este é o pressuposto a ser aqui discutido. Para tanto, elegeu-se construir a análise com base no Material Didático do Programa Esporte e Lazer da Cidade (BRASIL, 2004 e 2008³), além dos Planos Plurianuais. Trata-se, portanto, de uma análise que se pretende documental e do tipo descritiva.

\section{Nos matizes de uma razão estatizante na configuração do Estado brasileiro}

Ao apresentar uma genealogia da razão desestatizante para entender o Estado no contexto do modelo neoliberal, Bursztin (1998) observa que a instauração do discurso salvacionista durante a década de 90 nos países menos desenvolvidos foi o resultado do modelo desestatizante dos países ricos nos anos 80 , indicando que houve uma transplantação de uma realidade para outra, com um lapso temporal significativo correspondente a uma década. Esse modelo de transplantes não é, todavia, novidade, basta recordar o binômio colonizador-colonizado premente no debate durante décadas na América Latina, que se remete à tentativa de decifrar "os enigmas da realidade colonizada com fórmulas elaboradas para o mundo colonizador” (BURSZTIN, 1998: 143). Com essa apropriação, pretende-se evidenciar que o desenvolvimento de cada

\footnotetext{
${ }^{3}$ Em função da extensão do nome, será utilizado ao longo do texto o termo MATERIAL DIDÁTICO. Este documento constitui o manual de orientação, produzido pela Secretaria Nacional de Desenvolvimento do Esporte e Lazer do Ministério do Esporte a fim de basilar a formação dos agentes sociais do programa, bem como orientar coordenadores e gestores de núcleos do programa para os procedimentos a serem adotados em relação ao estabelecimento de convênios com o Ministério do Esporte. Documento cedido pelo Ministério do Esporte, ao qual agradecemos a colaboração para fins de pesquisa.
} 
sociedade produz conformações particulares, que em suas especificidades podem assumir formas variadas, resultando em formações de Estados nacionais próprios conforme cada momento (BURSZTIN, 1998).

Todavia, como salienta Timsit (1987), o número de elementos constitutivos de uma administração central tem sido ampliado ao longo da história, e mesmo tendo-se em consideração que cada Estado constitui uma experiência individual, o conjunto dos casos pode vislumbrar uma tendência geral de crescimento, particularmente, considerando o tamanho das estruturas administrativas a partir do século XVIII. Neste sentido, vale destacar que a França e a Inglaterra, por exemplo, apresentaram ao longo de sua história uma variação de cinco para quarenta pastas ministeriais, no caso da França, de cinco para trinta pastas, no caso inglês.

No Brasil, atualmente, a estrutura administrativa apresenta 23 ministérios, 8 secretarias e 6 órgãos, que gozam, assim como as secretarias, de status de ministérios, são eles: Agricultura, Pecuária e Abastecimento; Cidades; Ciência e Tecnologia; Comunicações; Cultura; Defesa; Desenvolvimento Agrário; Desenvolvimento, Indústria e Comércio Exterior; Desenvolvimento Social e Combate à Fome; Educação; Esporte; Fazenda; Integração Nacional; Justiça; Meio Ambiente; Minas e Energia; Planejamento, Orçamento e Gestão; Previdência Social; Relações Exteriores; Saúde; Trabalho e Emprego; Transportes; Turismo e, ainda, as secretarias que têm o mesmo status que os ministérios: Secretaria Especial de Aqüicultura e Pesca; Secretaria de Comunicação Social; Secretaria Especial dos Direitos Humanos; Secretaria Especial de Políticas de Promoção da Igualdade Racial; Secretaria Especial de Políticas para as Mulheres; Secretaria Especial de Portos; Secretaria-Geral da Presidência; Secretaria de Relações Institucionais; e, os órgãos que gozam do mesmo status dos ministérios: AdvocaciaGeral da União; Banco Central; Casa Civil da Presidência da República; Controladoria- 
Geral da União; Núcleo de Assuntos Estratégicos; Gabinete de Segurança Institucional (BRASIL, 2009).

Conquanto em relação ao crescimento no número de pastas no organograma da administração do Estado brasileiro, registra-se que do período pós-independência até o início da República tivemos uma administração marcada pela herança colonial com um aparelho estatal compresso. Posteriormente, o Estado vai agregando novas funções e a máquina vai se redesenhando tal qual o modelo europeu. O sentido dessa incorporação de funções por parte do Estado tem dois eixos centrais: o primeiro, diz respeito à incorporação de atividades que já existiam anteriormente, mas não em escala universalizada no âmbito estatal; o segundo, a eclosão de uma preocupação social, que se torna objeto de regulação e regulamentação (BURSZTIN, 1998). É neste contexto que se tem a criação de uma pasta exclusiva para o Esporte no Brasil e, particularmente, uma secretaria - que compõe a estrutura do novo ministério - destinada a definir políticas para o lazer, qual seja a Secretaria Nacional do Desenvolvimento do Esporte e Lazer.

Criado em 2004, este programa social se insere no quadro de políticas sociais do Governo Lula da Silva (2003-atual), isto porque os Planos Plurianuais mostram que constava na carta de intenções das consecutivas gestões (1996-2006) a intenção de promover o desenvolvimento de ações direcionadas para o esporte, visando ao aperfeiçoamento dos programas já existentes, com o incremento de uma política de formação para esse setor no Brasil (com base em pesquisa documental, 2007). Vale destacar que a criação do Programa coincide com a mudança de governo e com a reestruturação da configuração administrativa do Governo brasileiro, naquilo que, como observado com base em Bursztin (1998), diz respeito às novas funções assumidas pelo 
aparelho estatal, conforme um modelo de Estado que vai se redesenhando tal qual o modelo europeu.

A incorporação de funções por parte do Estado e adoção de políticas de cunho social de forma setorial, como ocorre com a criação de uma pasta exclusiva para o esporte em 2003, tem repercussão direta na destinação de recursos apresentados para o Ministério do Esporte no orçamento geral da União (SUASSUNA e AZEVEDO, 2007).

Segundo dados do Ministério do Planejamento (PPA 1996/1999), a destinação orçamentária do esporte no período de 1996 a 1999 superou áreas estratégicas como segurança. O esporte recebeu um total de 975 milhões de reais contra 826 milhões da segurança. Deste total, 385 milhões foram oriundos de fonte fiscal e seguridade; 248 milhões de recursos externos; 165 milhões de recursos privados e 177 milhões dos estados e municípios. A cultura, no mesmo período, por exemplo, recebeu dotações inferiores, tendo um total de 546 milhões de reais, sendo 371 milhões de fonte fiscal; 12 milhões de recursos externos; 134 milhões de fonte privada; 22 milhões de estados e municípios e 6 milhões de outras fontes (BRASIL, 1996). Essa diferença pode sinalizar certa importância da pasta do esporte já durante a gestão do Presidente Fernando Henrique Cardoso. Crescimento que teve certa continuidade nos PPAs subseqüentes, pois entre os anos de 2004 e 2007, por exemplo, o único programa federal destinado ao lazer - que é o Programa Esporte e Lazer da Cidade - apresentou dotação gradativa com base no orçamento da União, tendo um pequeno refluxo no ano de 2005 , mas com recuperação em $2006^{4}$ (cf. BRASIL, 2004).

\footnotetext{
${ }^{4}$ Cf. planilha fornecida pela SNDEL em maio de 2007, se comparado aos recursos recebidos pela mesma dotação no ano de 2003, verifica-se que o Esporte Solidário havia recebido em 2003 aproximadamente o triplo de recursos recebidos pelo Esporte e Lazer da Cidade em 2004.
} 


\section{Entendendo a institucionalização do lazer no Brasil}

A criação do Ministério do Esporte e o reaparelhamento do Estado brasileiro no período considerado podem ser compreendidos, com base no pressuposto levantado por Burzstin (1998), por meio da busca por uma razão estatizante. Cabe neste momento entender o sentido da criação de uma secretaria destinada a focalizar o lazer como política nacional e verificar se o fato de haver certo investimento de recursos públicos destinados a políticas e programas sociais - com o olhar focado no Programa Esporte e Lazer da Cidade - trazem argumentos suficientes para defender a tese da estatização.

Apresentando um desenho estrutural das sociedades capitalistas, Santos $(1997)^{5}$ distingue cinco componentes elementares (unidade de prática social, forma institucional, mecanismo de poder, forma de direito e modo de racionalidade) e quatro tipos de espaços estruturais (doméstico, da produção, da cidadania, mundial). Importase aqui com o cruzamento do componente estrutural "modo de racionalidade" com os espaços estruturais. Ao cruzar-se o modo de racionalidade com o espaço doméstico, tem-se como resultado a maximização da afetividade; com a produção, tem-se a maximização do lucro; com o espaço da cidadania, tem-se a maximização da lealdade; e, por fim, com o espaço mundial, tem-se a maximização da eficácia.

Segundo as considerações do próprio autor, a compreensão geral do cruzamento das categorias apontadas permite indicar que a natureza política do poder não é um atributo exclusivo de determinada forma de poder. Além disso, a apropriação da leitura de Santos (1997) possibilita o entendimento de que não se pode eliminar a distinção Estado/sociedade civil, porque a não verificação da distinção pode levar a uma fluidez dessas instituições sociais, o que tende a ser perigoso em sociedades periféricas

\footnotetext{
${ }^{5}$ Quadro apresentado por Santos, Boaventura. (1997). Pela mão de Alice. O social e o político na pósmodernidade. $3^{\text {a }}$ ed. São Paulo: Cortez. P. 125.
} 
ou semiperiféricas (democracias delegadas), dotadas de sociedades civis débeis ou pouco autônomas.

Aproximando-se desse tipo de abordagem, pode-se ainda destacar que a fragilidade de sociedades de democracia delegada, isto é, regimes em que "quem vence as eleições para a presidência é habilitado a governar como ele ou ela acharem melhor, constrangido(a) apenas pelas conjunturas das relações políticas existentes e por um período de governo limitado pela Constituição" (O'DONNELL, 1991, p. 59) ratifica-se a necessidade de se atentar para a adoção de arranjos institucionais em que o espaço público torne-se um espaço de ação pública e não apenas em defesa de interesse privados ou "personificados", conforme argumenta DaMatta (1991) tratando do "jeitinho brasileiro". Conforme a abordagem do autor anteriormente reportado, o cerne da configuração assumida pela esfera pública brasileira está centrado no modelo cultural em que questões do tipo "você sabe com quem está falando?” fazem parte do repertório para entender o lugar do sujeito no contexto societal. Tem-se, assim, uma sociedade em que, muitas vezes, prevalecem vínculos pessoais, inclusive, na distribuição das funções e cargos do aparelho estatal.

Com efeito, em sociedades periféricas ou semiperiféricas, como por exemplo, o Brasil, e neste caso particular em função da sua configuração cultural, a importância assumida pela sociedade civil deve ser vista como elemento categórico na busca de legitimação de direito e no estabelecimento de uma agenda para as políticas sociais, como àquelas focadas no lazer, a fim de tornar-se um aspecto sinalizador da abertura de espaços de negociação dos atores sociais com a esfera pública (aqui entendida como Estado). 


\section{Universalização de direitos: o lazer em foco}

Ao tomar-se o Programa Esporte e Lazer da Cidade como um exemplo para entender o redesenho estatal, ateve-se aos seus princípios, diretrizes e objetivos. Conforme MATERIAL DIDÁTICO (BRASIL, 2008, s/p ${ }^{6}$ ), os princípios norteadores da política nacional de esporte e lazer são:

1. Da reversão do quadro atual de injustiças, exclusão e vulnerabilidade social;

2. Do esporte e do lazer como direitos de cada um e dever do Estado;

3. Da universalização e inclusão social;

4. Da democratização da gestão e da participação.

Parece salutar destacar algumas contradições em relação aos princípios norteadores do PELC, isto porque, ao tempo em que o texto documental elenca que o esporte e o lazer devem ser reconhecidos como direitos sociais, aponta que um princípio da política nacional é reverter o quadro de injustiças, exclusão e vulnerabilidade social, aspecto que, inclusive é ratificado posteriormente no terceiro princípio que trata da universalidade e da inclusão social. Nos termos do próprio MATERIAL DIDÁTICO, o Programa Esporte e Lazer da Cidade visa, em síntese, "suprir a carência de políticas públicas e sociais que atendam às crescentes necessidades e demandas da população por esporte recreativo e lazer, sobretudo daquelas em situação de vulnerabilidade social e econômica, reforçadoras pelas condições de injustiça e exclusão social a que estão submetidas" (BRASIL, 2008, s/p).

Ora, se há a clareza por parte de quem define as políticas públicas de que adotando o esporte e o lazer como direitos - de forma universalizada - resolveria o problema da exclusão no país, por que, efetivamente, não se pode afirmar que a

\footnotetext{
${ }^{6}$ Esse documento apesar de ser impresso não conta com numeração de páginas. Fonte: banco de dados da Rede Cedes/UnB, 2008.
} 
população brasileira pode ser considerada socialmente incluída? A resposta parece simples, a exclusão social não se resolve com o acesso apenas ao esporte e lazer, mas como a universalização de direitos sociais e o exercício da cidadania, e, principalmente, com a possibilidade de empoderamento dos atores sociais participes do processo (SANTOS, 1997).

Como esclarece Dupas (1998, p. 122) a respeito da complexidade e polissemia do conceito de exclusão social:

Essa complexidade é expressa com clareza na referência feita ao conceito pelo Comissariado Geral de Planejamento do governo francês: "A noção de exclusão social é saturada de significados, não-significados e contra-significados. Pode-se fazer quase qualquer coisa com o termo, já que ele exprime o ressentimento daqueles que não podem obter aquilo que reivindicam".

A saturação de significados presentes no termo exclusão é similar ao significado do sentido de incluir, isto porque ambos os termos são neologismos, ou seja, é um fenômeno lingüístico - utilizado discursivamente por campos em disputa de interesses, numa espécie de jogos de linguagem - que tem por finalidade atribuir um novo sentido a uma palavra ou expressão que já existe. Desta forma, documentos oficiais - como o ora analisado - bem como discursos políticos acabam por utilizar de forma "naturalizada" as expressões inclusão e exclusão como se elas fossem autoexplicativas e pudessem ser apropriadas a distintas realidades sociais, estando por detrás uma compreensão equivocada em referência à sociedade capitalista, de que é possível incluir numa sociedade que se estrutura conforme diferenciações de classes sociais.

De outra parte, a atenção dada à capacidade de empoderamento dos atores sociais - ao passo em que se deve buscar a democratização e estimular a participação social - atende a um plano lógico no qual o engajamento dos atores nas relações de poder pode consistir na capacidade de transformação social, o que pressupõe uma 
cidadania ativa ${ }^{7}$. Dentro do sistema social em um contexto específico de tempo e espaço, o poder pressupõe relações regularizadas de autonomia e de dependência entre os atores e a coletividade dentro do contexto da interação social. Trata-se do que Giddens (2005) denomina de dialética do controle dos sistemas sociais.

O tema do controle dos sistemas sociais - mais propriamente da autoorganização comunitária; trabalho coletivo; intergeracionalidade; fomento e difusão da cultura local; respeito à diversidade; intersetorialidade - está apresentado nas diretrizes concernentes ao programa (BRASIL, 2008).

Ainda assim, parece coerente o elenco de objetivos propostos pelo Material Didático (BRASIL, 2008, s/p), a saber:

1. Democratizar o acesso a políticas de esporte e lazer;

2. Reconhecer e tratar o esporte e o lazer como direito social;

3. Articular ações voltadas para públicos diferenciados nos núcleos de esporte e lazer, de forma a privilegiar a unidade conceitual do programa;

4. Difundir a cultura do lazer através do fomento a eventos de lazer construídos e realizados de forma participativa com a comunidade;

5. Formação permanente aos agentes sociais de esporte e lazer (professores, estudantes, educadores sociais/comunitários, gestores e demais profissionais de áreas afins envolvidos no programa);

6. Fomentar e implementar instrumentos e mecanismos de controle social;

7. Aplicar metodologia de avaliação institucional processual às políticas públicas de esporte e lazer;

\footnotetext{
${ }^{7}$ Ver a respeito: SILVA, Cristina Nogueira da. Conceitos oitocentistas de cidadania. In. Análise Social. Lisboa: ICS, 2009. PP.533-563. Na compreensão do impacto do conceito de cidadania nos anos oitocentos, a autora apresenta uma interessante distinção dominante à época: cidadãos activos e cidadãos passivos. "Cidadãos activos eram todos os que, por reunirem condições psicológicas para a formação de uma vontade livre e autónoma, podiam intervir na formação dos poderes públicos por meio do voto e serem eleitos. Cidadãos passivos eram todos os que tinham direito à proteção dos seus direitos naturaiscivis, mas não exerciam o direito ao voto e não podiam ser eleitos (SILVA, 2009, p. 548).
} 
8. Fomentar a ressignificação de espaços esportivos e de lazer que atendam às características das políticas sociais de esporte e lazer implementadas e que respeitem a identidade esportiva e cultural local/ regional;

9. Orientar a estruturação e condução de suas políticas públicas de esporte e lazer nos poderes públicos municipais e estaduais.

Como se pode constatar cada um dos objetivos do PELC merece uma consideração especial, desta forma, passa-se a analisar por blocos: (a) democratização, universalização e acesso: neste bloco encontram-se os objetivos 1,2 , que tratam de democratizar o acesso e reconhecer e tratar o esporte e o lazer como direito social, bem como da difusão cultural, que reforça a necessidade de difundir a cultura do lazer através do fomento a eventos de lazer construídos e realizados de forma participativa com a comunidade. Estes objetivos se relacionam com todas as diretrizes elencadas, mas está calcado em formulações que se perfazem com base em concepções despidas de neologismos, o que remete a um discurso um tanto quanto cuidadoso por parte dos gestores e que correspondem a oportunizar o lazer a população brasileira de forma democrática e, portanto, participativa.

O segundo bloco diz respeito à formação permanente dos atores sociais envolvidos no programa (5). Este objetivo está relacionado à diretriz que corresponde à propiciar formação permanente aos agentes sociais de esporte e lazer (professores, estudantes, educadores sociais/comunitários, gestores e demais profissionais de áreas afins envolvidos no programa). A relevância deste objetivo atende a dois pressupostos básicos: (i) a necessidade de observar a coerência entre os referencias teóricometodológicos indicados pelo programa, bem como (ii) a possibilidade de submeter o que vem sendo construído em termos de práticas pedagógicas e de intervenção a 
discussões teóricas atuais, bem como observando o que está sendo produzido e analisado em termos de pesquisas científicas que venham a contribuir com o programa.

O respeito à difusão e diversidade culturais e a adoção de uma clara concepção de lazer são, por assim dizer, defendidos no sentido de reafirmar a necessidade de: difundir a cultura do lazer através do fomento a eventos de lazer construídos e realizados de forma participativa com a comunidade; fomentar a ressignificação de espaços esportivos e de lazer que atendam às características das políticas sociais de esporte e lazer implementadas e que respeitem a identidade esportiva e cultural local/ regional; articular ações voltadas para públicos diferenciados nos núcleos de esporte e lazer, de forma a privilegiar a unidade conceitual do programa; (3, 4 e 8) constam do terceiro bloco de análise (c). A esse respeito é necessário enfatizar a coerência destes objetivos com as diretrizes que tratam do esporte e do lazer como direitos de cada um e dever do Estado e da universalização e inclusão social, o que significa dizer que o documento apresenta uma coerência interna, com referência à relação diretrizes/objetivos. Mas, por outro lado, é necessário observar no documento analisado o norte conceitual adotado no que diz respeito ao termo lazer. Com efeito, apesar de o documento sinalizar na direção de apontar um claro referencial teórico para o termo, parece haver uma profusão de conceitos e concepções de lazer adotadas pela Secretaria Nacional de Desenvolvimento para o Lazer, posto que diferentes concepções teóricas vêm sendo, não só estimuladas, como também fomentadas e utilizadas no documento orientador para as ações dos núcleos do programa (BRASIL, 2008). Deste modo para o conceito de lazer - que nos documentos anteriores (BRASIL, 2004) era expressa com base em Mascarenhas (2004) - no manual de 2008 apresenta dois nortes teóricometodológicos distintos, ao passo em que insere ao lado da definição de Mascarenhas (2003) a compreensão de Marcelino (s/d), como segue: 
O Programa Esporte e Lazer da Cidade entende o lazer como um 'fenômeno tipicamente moderno, resultante das tensões entre capital e trabalho, que se materializa como um tempo e espaço de vivências lúdicas de organização da cultura, perpassado por relações hegemônicas' (Fernando Mascarenhas). Dialoga-se com a compreensão de tempo disponível que reflete sobre a característica da livre escolha da vivência ou da contemplação, da espontaneidade, do prazer e da felicidade. O duplo aspecto educativo pelo e para o lazer é um grande desafio de nosso programa e busca ser vivido a partir de diversas dimensões e conteúdos do lazer que vão além das atividades esportivas (MARCELLINO s/d, citado por BRASIL, 2008, s/p).

O que se pode apontar em relação ao uso de referencias teórico-metodológicas distintos, com compreensões diferenciadas de lazer, é que a falta de clareza na apropriação desses conceitos pode desembocar no uso inapropriado e na incompreensão daqueles que tentarão operacionalizar a definição no cotidiano dos núcleos. Assim, mostrar que o lazer é parte de um movimento dialético e contraditório presente na sociedade capitalista como faz o documento analisado com base nas formulações de Mascarenhas é diverso do trato dado ao lazer, com base no entendimento do mesmo como um tempo disponível no qual o indivíduo vivenciará a felicidade, de forma espontânea, contemplativa e com prazer. Esse tipo de apropriação teórica realizada pelo documento pode, a meu ver, correr o risco de desembocar numa espécie de neologismo anteriormente apontado em relação ao paradoxo exclusão/inclusão social. Isto porque ao referenciar marcos teóricos distintivos, sem clareza metodológica, pode-se recair na utilização de argumentos pseudo-concretos (aproveitando-se aqui a clássica argumentação de Karel Kosik sobre a pseudo-concreticidade presente na dialética do concreto) (KOSIK, 1989).

Na sequência, o tema a ser tratado tem referencia com a participação social e seus mecanismos de controle, correspondendo ao quarto bloco (d) de análise. Sobressaem-se os objetivos 6, 7 e 9, que afirmam a necessidade de fomentar e implementar instrumentos e mecanismos de controle social; aplicar metodologia de avaliação institucional processual às políticas públicas de esporte e lazer; orientar a 
estruturação e condução de suas políticas públicas de esporte e lazer nos poderes públicos municipais e estaduais.

Este conjunto de objetivos está relacionado com a diretriz que evoca os preceitos da democracia participativa, isto é, da democratização da gestão e da participação (BRASIL, 2008). O aspecto a ser aqui destacado diz respeito à participação da sociedade civil nos processos decisórios e na instancia de fiscalização do programa. Os objetivos descritos e a diretriz apresentada refletem o respeito do texto documental analisado à democracia participativa, o que também pode assistir ao documento coerência interna.

Para tanto, pode-se lembrar do que ressalta Bobbio (1990, p. 407), a respeito da relação Estado e sociedade civil, quando afirma que:

O Estado não pode, portanto, limitar-se a criar políticas sociais tendentes a assegurar complementarmente a integração do mercado. Pelo contrário, tem de fazer face à perda de controle social, que se manifesta essencialmente como crise de motivação... em relação aos valores tradicionais do individualismo e do profissionalismo, pondo em ação uma rede de vigilância e controle, que compreenda, não só a ampliação do aparelho policial, como também o incremento de vastos setores do chamado trabalho social $[\ldots]$

Diante das considerações do autor a respeito do papel do Estado, cabe destacar, além da relação estabelecida entre Estado e sociedade civil, a formulação por parte do Estado de políticas sociais (programas e ações). Trata-se da necessidade, reforçada por Bobbio, com fundamento em Habermas, de que o Estado deve fazer face aos interesses individuais, portanto, deve possibilitar a definição de políticas que visem ao coletivo e que estão na esfera daquilo que comumente se chama sociedade civil, entendida como:

[...] o conjunto das instituições responsáveis pela representação dos interesses de diferentes grupos sociais, bem como pela elaboração e/ou difusão de valores simbólicos, de ideologias, compreendendo o sistema escolar, os partidos políticos, as igrejas, as organizações profissionais, os sindicatos, os meios de comunicação, as instituições de caráter científico e artístico (COUTINHO, 1996, p. 54). 
No entanto, ainda que a sociedade civil ocupe lugar de destaque e se torne na atualidade um importante espaço/tempo de negociação - como registra Coutinho (1996), as formas de poder social que se apresentam estão dispostas conforme modos de racionalidades em clivagens polissêmicas (revestidas muitas vezes de discursos neologistas) que se perdem no emaranhado de teias e redes que agregam atores e direitos sociais, como o lazer. Deste modo o fato de o documento (BRASIL, 2008) contemplar o maior envolvimento da sociedade civil no processo de construção contínua do programa numa coerente relação diretriz-objetivos, pode indicar uma visão de Estado que prima pela busca de diálogo com a sociedade civil, mas não assegura que na prática os interesses individuais não prevalecerão. Ainda assim em relação às diretrizes intergeracionalidade e intersetorialidade, os objetivos do programa que preservam a mobilização social não são suficientemente consistentes para apontar a realização das mesmas na execução do programa e, por fim, o fato de não haver clareza metodológica do documento (BRASIL, 2008) em relação ao principal conceito a ser focalizado no programa - o lazer - pode incorrer na construção de uma costura mal feita e possibilitar o aparecimento de brechas do ponto de vista teórico-metodológico na execução do programa nos seus núcleos.

\section{Considerações finais}

A perspectiva aqui apresentada buscou analisar a conformação do Estado brasileiro, bem como o espaço destinado neste construto às políticas sociais (programas e ações), focalizando o lazer como tema central. Para tanto, discutiu-se o significado do Estado, o paradoxo estabelecido entre Estado e sociedade civil, vislumbrando-se os mecanismos estratégicos de participação e mobilização social visando aos direitos sociais. Neste ínterim, procurou-se entender o lugar da razão (des)estatizante no processo (BURZSTIN, 1998), bem como sua ressignificação no atual contexto político 
brasileiro - caso dos últimos governos - Fernando Henrique Cardoso e Lula da Silva (1996-atual).

As considerações apontam que a redefinição do Estado brasileiro culmina com outra racionalidade, especialmente no âmbito da institucionalização de políticas setoriais para o esporte e lazer, com base na criação do Ministério do Esporte em 2003 e na focalização do lazer no campo das políticas sociais. Com base nesse cenário, é importante destacar os arranjos institucionais constituídos no caso particular do Brasil como uma democracia delegada - atentando para o organograma estatal e a disposição ministerial, que tende para a adoção de um modelo ampliado e que se perfaz pela relativa importância da questão social no âmbito das pastas ministeriais, convergindo com a idéia de um novo desenho institucional, que culmina com a criação de vários ministérios voltados para políticas sociais, inclusive uma destinada ao esporte e ao lazer.

Ao eleger-se como recorte para a reflexão o lazer e, por conseguinte, o Programa Esporte e Lazer da Cidade e a criação do Ministério do Esporte pretendeu-se sistematizar, com base em uma experiência em processo de consolidação de política social (programa social), no quadro de uma democracia delegada (O'DONNELL, 1991 e SANTOS, 1997), alguns elementos para entender motivações e perspectivas das iniciativas de políticas recentes. Neste sentido, vale destacar aspectos como o reaparelhamento estatal e a "nova" conformação administrativa adotada, bem como a destinação de recursos orçamentários para as políticas de cunho social, particularmente àquelas destinadas ao lazer como direito social. Contudo, também se apresenta uma crítica em relação a pouca clareza na utilização de uma concepção de lazer como norte para definir a política (programa) e que pode por essa razão suscitar percalços na execução do programa, por meio de utilizações de expressões que se revestem de 
neologismos como: exclusão/inclusão social ou mesmo a adoção de distintos referenciais teórico-metodológicos para a conceituação do lazer, principal conceito a ser tratado no documento Material Didático (BRASIL, 2008).

\section{REFERÊNCIAS}

BOBBIO, Noberto. Dicionário de política. Brasília: Editora da Universidade de Brasília, 1990.

BRASIL. (1996). Plano plurianual 1996/1999. Brasília: Ministério do Planejamento. . (2004). Plano plurianual 2004/2007. Brasília: Ministério do Planejamento. . (2008). Material didático do Programa Esporte e Lazer da Cidade. Brasília: Ministério do Esporte.

. (2009). Governo Federal: estrutura ministérios. Disponível em: http://www.brasil.gov.br/governo_federal/estrutura/ministerios/. Acesso em: 27 maio 09.

BURZSTIN, Marcel. Introdução à crítica da razão desestatizante. Revista do Serviço Público (Brasília), BRASÍLIA, v. 1, n. 1, p. 141-163, 1998.

COUTINHO, Carlos Nelson. Marxismo e política: a dualidade de poderes e outros ensaios. São Paulo: Cortez, 1996.

DAMATTA, Roberto. A casa e a rua. Rio de Janeiro: Guanabara Koogan, 1991.

DUPAS, Gilberto. A lógica da economia global e a exclusão social. Estudos. Avançados. [online]. 1998, vol.12, n.34, pp. 121-159. ISSN 0103-4014.

GIDDENS, Anthony. (2005). The New Egalitarianism Cambridge : Polity Press.

KOSIK, Karel. (1989). Dialética do concreto. Rio de Janeiro: Paz e Terra.

MARCARENHAS, Fernando. (2004). Lazer como prática da liberdade. 2. ed. Goiânia: Ed. UFG.

O’DONNELL, Guillermo. "Democracia Delegativa?" In: Novos Estudos. n.31, São Paulo: CEBRAP, 1991, p. 25-40

SANTOS, Boaventura. Pela mão de Alice. O social e o político na pós-modernidade. 3. ed. São Paulo: Cortez, 1997. 
SILVA, Cristina Nogueira da. Conceitos oitocentistas de cidadania. In. Análise Social. Lisboa: ICS, 2009. pp.533-563

SUASSUNA, Dulce e AZEVEDO, Aldo. Política e Lazer: interfaces e perspectivas. Coleção Dossiê. Brasília: Thesaurus Editora, 2007.

TIMSIT, Gerard. Administrations et Etats: etude comparee. Paris: Presses Universitaires de France, 1987.

\section{Endereço da Autora:}

Dulce Filgueira de Almeida

Campus Universitário Darcy Ribeiro, Gleba B, FEF

Universidade de Brasília

Brasília - DF - CEP 71910900

Endereço eletrônico: dulce@unb.br 